Kapata Arkeologi, 13(2), 223-232

ISSN (cetak): 1858-4101

ISSN (elektronik): 2503-0876

http://kapata-arkeologi.kemdikbud.go.id

\title{
LUBANG TAMBANG BATU BARA BAYAH: JEJAK ROMUSHA DI BANTEN SELATAN
}

\author{
Bayah Coal Mining Pit: The Trail of Romusha in South Banten
}

\author{
Iwan Hermawan \\ Balai Arkeologi Jawa Barat - Indonesia \\ Jalan Raya Cinunuk Km. 17 Cileunyi, Bandung 40623 \\ iwan1772@gmail.com
}

Naskah diterima: 08/09/2017; direvisi: 03/10—14/11/2017; disetujui: 17/11/2017

Publikasi elektronik: 30/11/2017

\begin{abstract}
Romusha was a form of labor force mobilization during the Japanese occupation. They are employed to build military infrastructure and explore mining or digging foxholes. One of the center of romusha was Bayah in South Banten. Romusha were came from different parts of Java Island and employed in the Bayah Kozan coal mine. The coal mining system carried out in Bayah, is a closed mine. Mining is done by making a hole to reach ader (ore tree). The mining pits and coal mining activities were conducted with simple equipment under the pressure and torture of the Japanese soldiers who supervised romusha. This paper aims to uncover traces romusha in South Banten through the remains of Japan in the form of Coal Mine Hole. The writing method used is descriptive analysis. Data collection through the activities of literature studies, field surveys, and interviews. The suffering experienced by the romusha in Bayah reflected from the pits where coal mines are numerous in the region Gunungmadur Bayah.
\end{abstract}

Keywords: Mining, coal, romusha, Bayah

\begin{abstract}
Abstrak
Romusha merupakan bentuk mobilisasi tenaga kerja pada masa Pendudukan Jepang. Mereka dipekerjakan untuk membangun sarana prasarana militer dan menggali bahan tambang atau lubang perlindungan. Salah satu daerah yang menjadi tempat pemusatan romusha adalah Bayah di Banten Selatan. Mereka berasal dari berbagai daerah di Pulau Jawa dan dipekerjakan di tambang batu bara Bayah Kozan. Sistem penambangan batu bara yang dilakukan di Bayah adalah tambang tertutup. Penambangan dilakukan dengan cara membuat lubang untuk mencapai ader, yaitu pohon bijih. Kegiatan penggalian lubang tambang dan penambangan batu bara dilakukan dengan peralatan sederhana di bawah tekanan dan siksaan tentara Jepang yang menjadi pengawas romusha. Tulisan ini bertujuan untuk mengungkap jejak romusha di Banten Selatan melalui tinggalan masa Jepang berupa lubang tambang batu bara. Metode penulisan yang digunakan adalah deskriptif analisis. Pengumpulan data melalui kegiatan studi pustaka, survei lapangan, dan wawancara. Penderitaan yang dialami oleh para romusha di Bayah tergambar dari keberadaan lubang-lubang tambang Batu bara yang banyak terdapat di kawasan Gunungmadur, Bayah.
\end{abstract}

Kata kunci: Lubang tambang, batu bara, romusha, Bayah

\section{PENDAHULUAN}

Bayah secara administratif merupakan salah satu Kecamatan di Kabupaten Lebak Provinsi Banten dengan luas 156,43 Ha. Kecamatan Bayah berbatasan dengan Samudera Hindia di Selatan, Kecamatan Panggarangan di Barat, Kecamatan Cibeber di Utara, dan Kecamatan Cilograng di Timur. Secara Geografis Kecamatan Bayah berada di Pesisir Selatan Pulau
Jawa dengan topografi dataran pantai serta pegunungan dan Perbukitan. Wilayah ini berada pada ketinggian 0 mdpl sampai 388 mdpl. Kecamatan Bayah membawahi 11 Desa, yaitu Desa Bayah Barat, Desa Darmasari, Desa Sawarna, Desa Cidikit, Desa Bayah Timur, Desa Cimancak, Desa Suwakan, Desa Pasirgombong, Desa Cisuren, Desa Pamubulan, dan Desa Sawarna Timur. 
Bentang alam Kawasan Bayah berupa perbukitan, lembah dan pesisir dengan garis pantai yang sempit dan pada beberapa titik pantainya bertebing terjal. Kawasan ini merupakan bagian dari zona depresi antar montana (zona Bandung). Kondisi struktur geologi Kubah Bayah kompleks, bercampur antara lipatan, sesar, pengangkatan, terobosan batuan beku, dan endapan gunung api tua. Umur batuannya terentang dari Eosen hingga Pliosen. Morfologi Kawasan Bayah secara keseluruhan dikenal sebagai kubah (dome) dan dinamakan Kubah Bayah (Bayah Dome). Tiga sungai besar mengalir di kawasan kubah ini, yaitu Ci Bareno di bagian sayap timur. Ci Madur di bagian tengah, dan Ci Peucangceuri di bagian barat kubah. Pada bagian tengah hingga pantai selatan Kubah Bayah membentang kawasan kars (Van Bemmelen, 1949: 42).

Kubah Bayah merupakan suatu antiklinorium yang rumit dan cembung ke arah utara akibat mengalami perlipatan yang kuat. Batuan penyusunnya berupa batuan sedimen yang berumur Neogen disertai intrusi yang berbentuk volcanic neck, stock, dan bos (Van Bemmelen, 1949: 42). Berdasarkan Peta Geologi Lembar Leuwidamar, batu gamping penyusun karst di kawasan ini termasuk anggota dari Formasi Citarate yang terbentuk pada lingkungan terumbu di belakang paparan terbuka, yang kadang tenggelam oleh naiknya muka laut setempat. Kondisi Geologi dan Tektonik yang terjadi di Kubah Bayah membentuk berbagai jenis bahan galian, yaitu bahan galian logam dan bahan galian nonlogam. Bahan galian logam seperti emas (Au) dan mineral pengikutnya, antara lain galena $(\mathrm{Pb})$, seng $(\mathrm{Zn})$, tembaga $(\mathrm{Cu})$, pirit $(\mathrm{Fe})$, dan batu besi. Bahan galian lainnya berupa bahan galian nonlogam dan bahan galian industri, yaitu batu gamping, kalsit, batu belah, zeolit, lempung, tras, feldsfar, batu pasir kuarsa, pasir darat, bentonit, kaolit, batu sempur oval, sirtu, dan batu bara (Sujatmiko \& Santosa, 1992).

Potensi batu bara di Bayah merupakan satusatunya di Pulau Jawa. Berbeda dengan cadangan batu bara di Sumatera yang terpusat, cadangan batu bara Bayah tersebar di sepanjang Pesisir Selatan Banten, terutama di Cihara, Panyaungan, dan Gunung Madur. Saat ini eksploitasi batu bara skala kecil dilakukan oleh masyarakat Bayah dengan sistem tambang tertutup, yaitu menggali lubang vertikal dan atau horizontal dengan ukuran rata-rata 1 x 1 meter untuk mencapai ader (pohon bijih) untuk selanjutnya mengikuti arah ader tersebut. Sistem penambangan tertutup yang dilakukan oleh para penambang di Bayah disebabkan karena karakteristiknya berbeda dengan batu bara di Sumatera dan Kalimantan. Batu bara di Banten Selatan berusia Miosen dengan ader (pohon bijih) berada di bawah permukaan dengan ketebalan $0,5-2 \mathrm{~m}$ sehingga akan tidak ekonomis jika dilakukan penambangan terbuka.

Keberadaan Bayah sebagai daerah yang kaya akan barang tambang sudah diketahui jauh sebelum datangnya bangsa Jepang. Penelitian berkenaan dengan keberadaan bahan tambang sudah dilakukan sejak akhir abad ke-19 dan semakin intensif pada awal abad ke-20. Penelitian tentang Geologi di Banten Selatan, khususnya Bayah dan Cikotok sudah dilakukan pada kurun waktu tahun 1839-1916 oleh para peneliti, yaitu Homer, Hasaki, Junghunh, Verbeck, Fenaema Van Es, dan Zungler. Pada penelitian-penelitian tersebut ditemukan indikasi endapan Emas di daerah Bayah, Cimandiri, dan Cikotok (Hermawan, 2013). Potensi bahan tambang di Kubah Bayah yang dilaporkan oleh para peneliti tersebut mendorong perusahaan pertambangan swasta Belanda, NV. Mijnbouw Maatschappy Zuid Bantam (NV. MMZB) pada tahun 1939 membuka tambang emas di Cikotok setelah melalui proses persiapan selama tiga tahun, yaitu 1936-1939. Sejak saat itu, Cikotok menjadi salah satu kota tambang di Nusantara. Kegiatan penambangan pertama kali dilakukan di Blok Cikotok dan Cipicung, kemudian menyusul Blok Cirotan. Pabrik pengolahan bijih emas dibangun di Pasirgombong dan pengangkutan hasil tambang ke pabrik pengolahan dilakukan dengan menggunakan Lori Gantung (Hermawan, 2014: 16). Potensi batu bara di Bayah yang juga disinggung oleh hasil penelitian para ahli tersebut kurang menarik perhatian perusahaan tambang untuk mengeksploitasi karena dianggap kurang ekonomis. Biaya operasional lebih mahal dibanding dengan pendapatan yang diperoleh.

Kondisi tersebut berubah drastis ketika masuknya Jepang ke Indonesia pada tahun 1942. Tambang Cikotok diambil alih Jepang dan semua aktivitas pertambangan dihentikan, kecuali di lubang tambang Cirotan tetap berjalan untuk menambang timah hitam atau timbal $(\mathrm{Pb})$ yang merupakan bahan baku mesiu (Hermawan, 2014: 16). Potensi bahan tambang lainnya yang dilirik Jepang untuk dieksploitasi adalah batu bara. Hal 


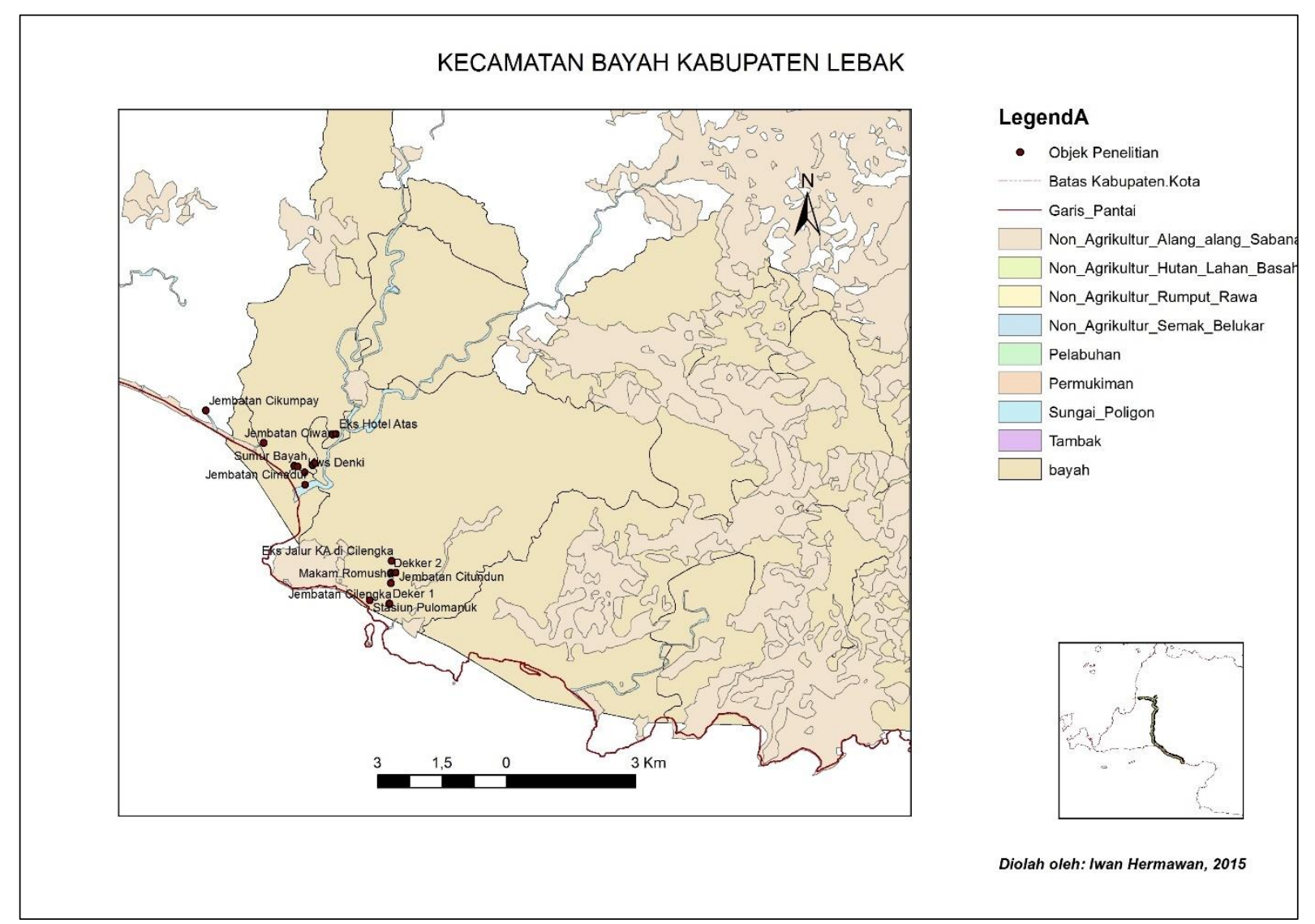

Gambar 1. Kecamatan Bayah, Kabupaten Lebak

(Sumber: Hermawan, 2015)

ini disebabkan tingginya kebutuhan batu bara untuk memenuhi kebutuhan perang dan tuntutan kemandirian energi daerah pendudukan. Guna melakukan eksploitasi potensi batu bara Bayah, Pemerintahan Militer Jepang berkerja sama dengan Sumitomo mendirikan perusahaan pertambangan, yaitu Bayah Kozan Sumitomo Kabusyiki Kaisya atau Mitsui Kosha Kabushiki Kaisya atau masyarakat luas mengenalnya dengan nama Bayah Kozan (Malaka, 2005: 53). Tanggung jawab operasional perusahaan menjadi bagian Tentara Angkatan Darat ke-16 Jawa, sedangkan permodalan menjadi tanggung jawab Sumitomo (Poeze, 1999: 300).

Pada pelaksanaannya, pertambangan batu bara tidak hanya terpusat di Bayah, namun menyebar di banyak titik di sepanjang Pantai Selatan Banten, dari Malingping sampai Sawarna sepanjang $30 \mathrm{~km}$. Jepang membangun pusat aktivitas pertambangan di tiga lokasi, yaitu Blok Madur, Blok Cihara (Cibobos), dan Blok Cimeng di Panyaungan (Panggarangan). Pusat administrasi perusahaan Bayah Kozan dibangun di Bayah, tidak jauh dari Blok Madur sebagai
Blok Penambangan Batu bara terbesar di Bayah. Pada setiap blok penambangan dibangun berbagai fasilitas tambang, yaitu: bedeng pekerja, kantor cabang, markas Kempetai, klinik, dan stasiun kereta api lengkap dengan tempat penampung batu bara. Untuk memenuhi kebutuhan tenaga kerja di Pertambangan Bayah, Pemerintah Militer Jepang melakukan mobilisasi tenaga kerja yang dikenal dengan istilah romusha. Mereka didatangkan dari berbagai daerah di luar Bayah, terutama dari Jawa Tengah dan jawa Timur. Mereka direkrut menjadi romusha oleh aparat desa atau Militer Jepang dan mereka tidak bisa menolak apa pun alasannya. Mereka tidak punya pilihan karena takut penolakan akan berdampak pada diri dan keluarga (Perdana, 2010: 153).

Selama di Bayah, para romusha ditempatkan terpisah dari penduduk pribumi, yaitu di bedeng-bedeng dekat lubang tambang. Mereka harus bekerja tanpa mengenal lelah membuka hutan, membangun jaringan rel kereta api, dan menggali lubang-lubang tambang. Mereka bekerja dengan menggunakan peralatan seadanya dan di bawah tekanan serta siksaan 
tentara Jepang. Kondisi tersebut diperparah dengan asupan makanan tidak layak serta kondisi lingkungan yang berat. Kondisi ini menyebabkan banyak romusha yang meninggal dunia akibat beratnya pekerjaan, beratnya siksaan, dan akibat penyakit malaria serta koreng. Mayat-mayat para romusha tersebut seringkali dikubur seadanya secara massal di tempat mereka meninggal. Saat ini Bayah berubah menjadi salah satu kawasan Industri di Banten Selatan. Lubang-lubang tambang peninggalan Jepang yang banyak terdapat di Gunungmadur secara bertahap mulai tergusur aktvitas pertambangan dan Industri. Kondisi ini menjadikan ingatan komunal masyarakat terhadap masa lalu Bayah yang pernah menjadi pusat aktivitas romusha sedikit demi sedikit mulai hilang dari ingatan masyarakat, terutama generasi muda.

Pada tulisan ini diuraikan keberadan lubang tambang batu bara tinggalan masa Pendudukan Jepang di Kecamatan Bayah, Lubang tambang tersebut tersebar di pusat-pusat tambang batu bara masa Pendudukan Jepang, terutama di sekitar Gunungmadur. Adapun permasalahan yang ingin dibahas pada tulisan ini adalah: bagaimanakah hubungan antara keberadaan lubang tambang batu bara Bayah dengan aktivitas romusha di Banten Selatan?

\section{METODE}

Sesuai dengan permasalahan yang diajukan dan tujuan yang ingin dicapai pada tulisan ini, metode penulisan yang dipergunakan adalah deskriptif analitis dengan pendekatan kualitatif. Pengumpulan data dilakukan melalui kegiatan survei lapangan, wawancara, dan studi literatur. Kegiatan Survei dilakukan di kawasan yang diduga pada masa Pendudukan Jepang merupakan pusat aktivitas romusha, terutama kawasan Gunungmadur dan sekitarnya yang merupakan salah satu blok penambangan batu bara di Bayah. Saat ini, kawasan Gunungmadur merupakan bagian dari wilayah administrasi Desa Darmasari dan Desa Sawarna, Kecamatan Bayah, Kabupaten Lebak, Provinsi Banten.

\section{HASIL DAN PEMBAHASAN}

Pada awalnya, peralihan kekuasaan dari Pemerintahan Kolonial Belanda ke Pemerintahan Pendudukan Jepang memberikan angin segar bagi bangsa Indonesia yang sedang berjuang meraih kemerdekaan. Kemenangan pasukan Kamikaze atas pasukan militer Belanda pada tahun 1942 menjadi pemantik semangat pejuang untuk melepaskan diri dari penjajahan Belanda. Kedatangan mereka ke Nusantara diterima dengan tangan terbuka dan dielu-elukan oleh masyarakat Indonesia karena dianggap sebagai saudara tua yang telah membantu bangsa Indonesia keluar dari cengkeraman penjajahan Belanda (Nagazumi, 1988: 30).

Simbol-simbol nasional diizinkan untuk dipamerkan bersama dengan simbol-simbol negara Jepang. Bendera merah putih berkibar berdampingan dengan bendera matahari terbit, demikian pula lagu kebangsaan Indonesia Raya dinyanyikan setelah lagu kebangsaan Jepang. Selain itu, Jepang juga membebaskan pemimpinpemimpin nasional yang ditahan oleh Belanda. Kebijakan tersebut tidak terlepas dari prinsip utama yang dipegang Jepang dalam menguasi bangsa Indonesia, khususnya Jawa, yaitu bagaimana menarik hati rakyat (minshin ha'aku) serta bagaimana mengindoktrinasi; menjinakkan mereka (senbu kosaku) (Yuliati, 2010: 2); dan mengusahakan agar daerah yang diduduki mampu memenuhi kebutuhan hidup sendiri (Ibrahim, 2004: 36). Hal ini dilakukan sebagai bentuk strategi Jepang dalam memenangkan Perang Asia Timur Raya. Semakin terbukanya serangan Sekutu ke wilayah-wilayah yang diduduki oleh Jepang, mendorong Pimpinan Tentara Jepang di Jawa, Jenderal Harada, mengambil keputusan untuk melakukan perlawanan dalam bentuk aksiaksi lokal jika Pasukan Sekutu mendarat di Jawa. Harada sadar bahwa Tokyo tidak akan mengirimkan divisi-divisi baru untuk membantu pertahanan di Jawa. Berkenaan dengan hal tersebut maka setiap Karesidenan di Jawa harus mampu memenuhi kebutuhan masing-masing dan menyimpan perbekalan dan perlengkapan perang (Frederick, 1989: 33).

Salah satu kemandirian yang harus dicapai oleh Penguasa Militer jepang di Pulau Jawa, adalah kemandirian di bidang energi. Hal ini disebabkan kebutuhan sumber energi Industri berupa batu bara didatangkan dari luar Jawa, yaitu dari Sumatera dan Kalimantan. Hal ini tidak mungkin dilakukan ketika masa perang, karena tongkang pembawa batu bara akan menjadi sasaran empuk bagi torpedo-torpedo Angkatan Laut Sekutu. Kondisi tersebutlah yang mendorong eksploitasi potensi batu bara Bayah, tujuannya agar Jawa dapat mandiri secara energi. Kegiatan penambangan batu bara di Bayah dilakukan melalui tiga tahapan, yaitu tahap 
perencanaan dan pembangunan yang dilakukan pada tahun 1942 sampai tahun 1943, serta tahap produksi atau penambangan yang dilakukan mulai tahun 1943 sampai Jepang kalah pada bulan Agustus tahun 1945.

Pada tahap perencanaan, aktifitas pertambangan yang dilakukan meliputi Survei dan pemetaan untuk menemukan dan menandai tempat-tempat yang mengandung batu bara dengan kualitas tinggi dan memungkinkan untuk eksploitasi. Aktivitas pada tahap pembangunan meliputi kegiatan pembukaan hutan untuk dijadikan areal tambang dan permukiman pekerja; penggalian terowongan utama di blok Madur, Blok Cihara, dan Blok Cimang; Pembangunan jalan, jembatan, jalur kereta api Saketi-Bayah (RG 1067), jalur kereta tambang atau Stingkul (RG 700); dan pembangunan infrastruktur pendukung perusahaan tambang, seperti perkantoran, perumahan pegawai, gardu induk listrik, sarana air bersih, dan rumah sakit (Hermawan, 2016: 37). Pembangunan jalur kereta api lintas Saketi-Bayah dilakukan dengan menggunakan rel-rel hasil bongkaran dari jalur lama yang tidak aktif dan tidak efisien (Tim
Telaga Bakti Nusantara, 1997: 146). Pada tahap produksi atau penambangan, para pekerja menambang batu bara di lokasi-lokasi yang telah ditetapkan sebelumnya, yaitu Blok Madur, Cihara, dan Cimang. Batu bara yang dihasilkan diangkut ke pusat-pusat penampungan dengan kereta api RG (Rail Gauge) 700 atau Stingkul (kereta tambang). Selanjutnya dari pusat-pusat penampungan, batu bara diangkut ke luar Bayah dengan menggunakan kereta api RG 1067. Jalur kereta api dibangun dari stasiun saketi di jalur Rangkasbitung-Labuan sampai pusat pertambangan batu bara di Bayah (Hermawan, 2015: 37; 2016: 12).

Salah satu lokasi penambangan batu bara di Bayah, adalah Blok Madur atau Gunungmadur. Blok Madur merupakan blok penambangan terbesar di kawasan pertambangan Bayah Kozan. Di kawasan ini banyak lubang bekas tambang batu bara dalam berbagai ukuran. Untuk lokasi penambangan yang besar, lubang atau terowongan utama memiliki kedalaman 100$750 \mathrm{~m}$ dengan tipe lubang Horizontal. Mulut lubang berdiameter 2,5-3,0 $\mathrm{m}$ dan di dalamnya terdapat kamar-kamar serta lorong-lorong cabang.

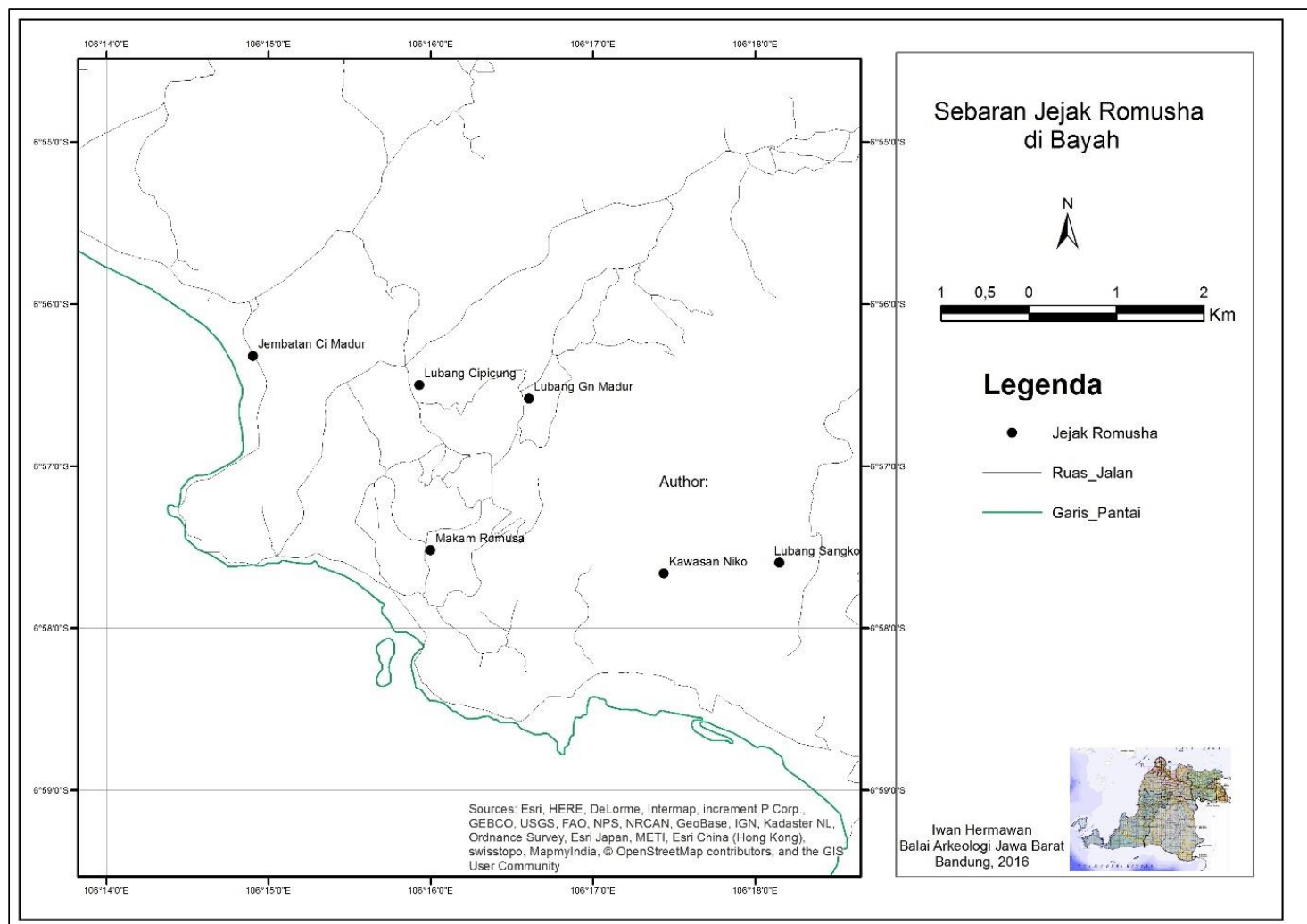

Gambar 2. Peta Sebaran Jejak Romusha di Bayah

(Sumber: Hermawan, 2016)

${ }^{1}$ Rail Gauge = Lebar Rel 
Sebagai penyangga dinding dan atap terowongan dipergunakan kayu. Pada bagian lantai terdapat rel lori pengangkut batu bara. ${ }^{2}$ Secara umum, lubang atau terowongan tambang batu bara di Bayah dibagi menjadi dua bagian, yaitu lubang totoire dan lubang jibangso. Lubang totoire merupakan terowongan utama yang merupakan tempat aktivitas keluar masuk romusha dan lori pengangkut batu bara. Lubang jibangso, merupakan jalur-jalur sempit di dalam totoire untuk menambang batu bara (Isnaeni \& Apid, 2008: 79).

Romusha yang bertugas di penambangan dikelompokkan dalam kelompok-kelompok kecil yang terdiri dari $10-12$ orang setiap kelompoknya. Setiap kelompok dipimpin oleh seorang kepala regu dengan anggota terdiri dari 2 orang pemegang bor, 2 orang ahli dinamit, dan sisanya adalah pemecah batu dan tukang angkut (Rohmanudin, 2012: 52). Penambangan dilakukan dengan cara meledakkan ader menggunakan dinamit. Pecahan dan reruntuhan batu bara berupa bongkahan dikumpulkan dan dipecah menjadi pecahan kecil untuk selanjutnya ditampung di lori yang akan mengangkutnya ke luar lubang. Pada banyak titik ader, terutama yang ukurannya kecil, penambangan dilakukan secara manual yaitu dengan menghancurkannya menggunakan belincong. Setelah banyak terkumpul, batu bara diangkut ke pusat penimbunan di stasiun Bayah dengan menggunakan stingkul. Saat ini, beberapa lubang tambang masih bisa ditemukan di Gunungmadur dan masyarakat menyebutnya sebagai lubang Jepang. Lubang-lubang tambang tersebut di antaranya: Lubang Cipicung, Lubang Cigalugur, Lubang Sangko, dan Gua Jepang di tepi pantai Gua Langgir.

\section{Lubang Cipicung}

Lubang Cipicung adalah salah satu lubang tambang di kawasan Gunungmadur yang masih bisa ditemukan. Lokasi lubang tambang berada di Kampung Sawah Desa Darmasari, tepatnya di hulu aliran Ci Picung, tidak jauh dari jalan lama penghubung Bayah-Cisolok. Kondisi mulut lubang tambang sudah longsor dan di atasnya terdapat pohon beringin. Pintu masuk lubang

\footnotetext{
2 Wawancara dengan Atok (74 tahun), tokoh masyarakat Desa Darmasari dan pernah memasuki Lubang Tambang Cipicung; dan Iyar (50 tahun), Warga Kampung Sawah, 2016.
}

tertutup longsoran di bagian tengahnya sehingga membentuk dua celah yang masih terbuka dengan ukuran masing-masing lebar $1,25 \mathrm{~m}$ dan tinggi 1,50 m. Lantai lubang tambang dipenuhi lumpur dan longsoran.

Pada bagian puncak bukit di atas lubang Cipicung terdapat lubang vertikal menyerupai sumur persegi dengan ukuran 1 x $1 \mathrm{~m}$. Sumur tersebut merupakan lubang tambang milik masyarakat yang tidak dilanjutkan untuk ditambang. Menurut keterangan Iyar (50 tahun), sumur tersebut mempunyai kedalaman $6 \mathrm{~m}$ dan lubang mendatar dengan panjang sekitar $6 \mathrm{~m}$ mengikuti ader. Ujung lubang mendatar bermuara di lubang Jepang, yaitu lubang Cipicung. Ruangan di dalam lubang Jepang tersebut relatif luas dan tinggi dengan penyangga balok-balok kayu yang tampaknya sudah rapuh. Batu bara di dalam cukup banyak ditemukan, akan tetapi penggalian tidak dapat dilanjutkan di sini karena tercium bau gas yang menyengat. ${ }^{3}$

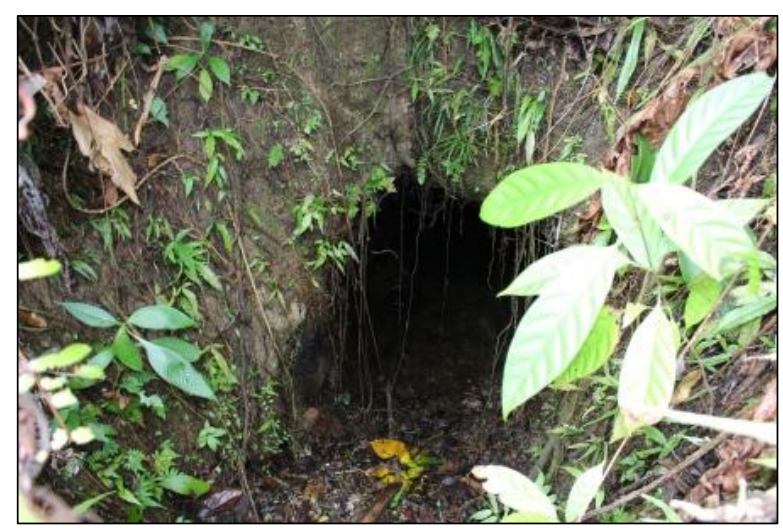

Gambar 3. Lubang Tambang Cipicung

(Sumber: Balai Arkeologi Jawa Barat, 2016)

Penjelasan tersebut dibenarkan oleh Atok (74 tahun), Tokoh masyarakat Darmasari, yang pernah masuk ke dalam lubang tambang Cipicung untuk mencari harta karun peninggalan Jepang. "Lubang tambang Cipicung di bagian dalamnya luas dan tinggi, panjang lubang dari pintu masuk lebih dari $500 \mathrm{~m}$ dengan banyak cabang. Cabangcabang tersebut ukurannya lebih kecil, bahkan ada lubang yang berbentuk celah sempit yang hanya bisa dimasuki oleh satu orang. Jalur lubang menanjak mengikuti kemiringan ader dan pada lantainya terdapat jalur rel. Pada bagian dalam

\footnotetext{
${ }^{3}$ Wawancara dengan Iyar (50 tahun), Penambang Batu bara tradisional warga Desa Darmasari Kecamatan Bayah, 2016
} 
lubang Cipicung terdapat 6 ruangan mirip kamar. Untuk menghindari ambruk, dinding dan atap lubang diperkuat dengan balok-balok kayu. ${ }^{4}$

Lubang tambang batu bara lainnya di kawasan Cipicung, adalah lubang 13. Lubang ini merupakan lubang horizontal dengan ukuran yang tidak jauh berbeda dengan lubang Cipicung. Saat ini lubang 13 sudah tidak dapat dikenali karena pintu masuk lubang tersebut sudah terkubur oleh longsoran material dari proyek pembangunan pabrik semen yang tepat berada di atasnya. Menurut keterangan masyarakat, di dalam lubang 13 masih terdapat mobil Jeep yang sengaja disembunyikan oleh tentara Jepang sebelum meninggalkan Bayah. ${ }^{5}$

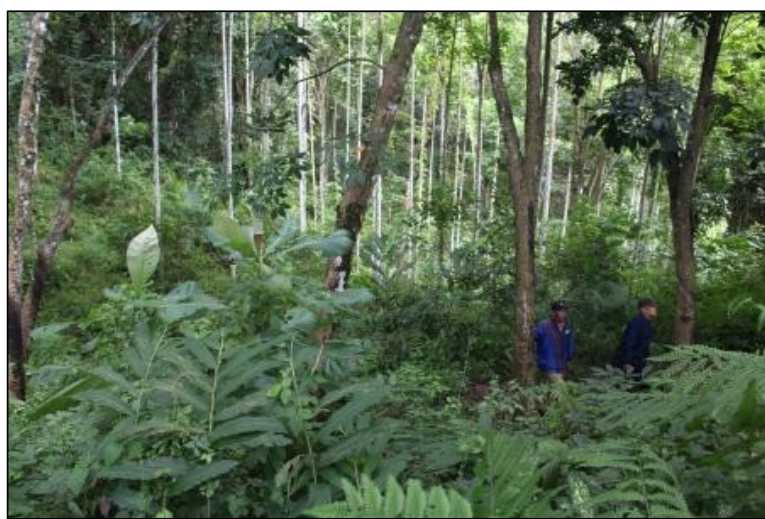

Gambar 4. Situasi lubang tambang Madur/Cigalugur (Sumber: Balai Arkeologi Jawa Barat, 2016)

\section{Lubang Cigalugur}

Lubang tambang Madur atau Cigalugur berada di hulu Ci Galugur berada di kawasan perkebunan karet Gunungmadur yang dikelola oleh PT. Perkebunan Kroewoek/PT. JA Wattie. Lokasi lubang tambang tidak jauh dari kompleks perumahan dan kantor Perkebunan, tepatnya di dasar lembah Cigalugur. Pada masa Pendudukan Jepang, kawasan ini merupakan pusat administrasi Bayah Kozan cabang Blok Madur6 . Saat ini lubang tambang sudah tidak dapat dikenali karena pintu lubang sudah tertutup longsoran material dan dipenuhi oleh ilalang dan tumbuhan perdu.

\section{Lubang Sangko}

Lubang Sangko merupakan salah satu lubang tambang batu bara pada masa Pendudukan

\footnotetext{
${ }^{4}$ Wawancara dengan Atok (74 tahun), tokoh masyarakat Desa Darmasari kecamatan Bayah, 2016

${ }^{5}$ Wawancara dengan Atok (74 tahun), HMS Badjadji (87 tahun), Iyar (50 tahun)
}

Jepang Lokasinya berada di kaki tebing curam di tepi sungai kecil. Lubang Sangko terletak di Kampung Sangko Desa Sawarna, Kecamatan Bayah. Lubang Sangko merupakan lubang tambang Horizontal dengan mulut lubang berukuran besar. Kondisi saat ini, mulut lubang Sangko sebagian besar tertutup longsoran dinding gua dengan bagian yang terbuka berukuran tinggi $1,30 \mathrm{~m}$ dan lebar $4 \mathrm{~m}$. Bagian dalam lubang dipenuhi oleh lumpur dan menjadi aliran air yang mengalir dari mata air di dalam gua. Pada beberapa bagian dinding dan atap lubang tampak bekas kayu penyangga lubang. Menurut keterangan Supandi (59 tahun), lumpur yang memenuhi lantai lubang Sangko mempunyai kedalaman lebih dari $1,5 \mathrm{~m}$. Jalur lubang tidak mendatar, namun menanjak mengikuti kemiringan ader. $^{7}$

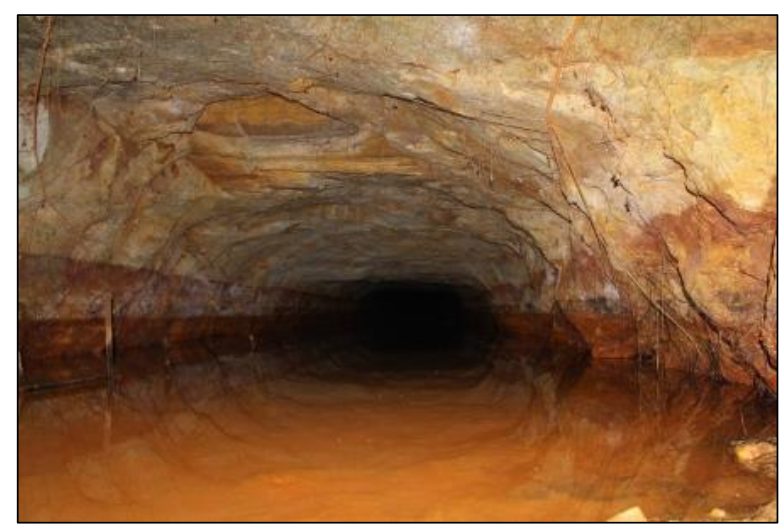

Gambar 5. Lubang Tambang Sangko

(Sumber: Balai Arkeologi Jawa Barat, 2016)

\section{Gua Jepang/Gua Hartakarun}

Gua Hartakarun atau Lubang Jepang merupakan gua buatan yang digali di tebing karst pantai Gua Langir, Desa Sawarna Kecamatan Bayah. Lokasi gua Jepang ini tidak jauh dari lubang Sanko, lubang Niko, dan pusat pengumpulan batu bara di Pulomanuk. Gua tersebut merupakan gua buatan untuk kepentingan pertahanan. Hal ini sesuai dengan apa yang disampaikan oleh Ibong (51 tahun) dan Supandi (59 tahun), penduduk Desa Sawarna yang mengungkapkan bahwa berdasarkan cerita orang tuanya, gua Jepang tersebut dibangun untuk markas tentara yang bertugas mengintai lautan. Selain itu, gua tersebut juga menjadi gudang

\footnotetext{
6 Wawancara dengan HMS. Badjadji (87 tahun), Tokoh masyarakat Bayah

7 Wawancara dengan Supandi (59 tahun), masyarakat kampung Sangko-Sawarna, 2016
} 
penyimpanan barang-barang yang dikirim melalui laut. Menjelang Jepang kalah dan meninggalkan Bayah, gua tersebut dihancurkan terlebih dahulu dengan menggunakan dinamit dan para romusha yang bekerja di gua tersebut ikut dikubur, tidak ada seorang pun yang lolos. ${ }^{8}$ Berkenaan dengan keberadaan Gua Hartakarun, HMS. Badjadji (87 tahun) mengungkapkan bahwa Gua tersebut sengaja digali oleh Jepang untuk mengawasi laut dan dihancurkan oleh tentara Jepang menjelang kepergian mereka dari Bayah. ${ }^{9}$

Saat ini, lubang Jepang/Gua Hartakarun merupakan salah satu gua di kawasan wisata pantai Gua Langgir. Pintu masuk sudah terkubur dan bahkan bagian dalam gua sudah terkubur oleh reruntuhan gua, karena seperti diuraikan sebelumnya, Gua Hartakarun sengaja dihancurkan Jepang. Sisa lubang tersebut hanya berupa ceruk, tinggi pintu lubang $2 \mathrm{~m}$ dan lebar 3 $\mathrm{m}$. Semakin dalam, ketinggian lubang semakin rendah dan tidak dapat dimasuki karena sudah terutup oleh reruntuhan.

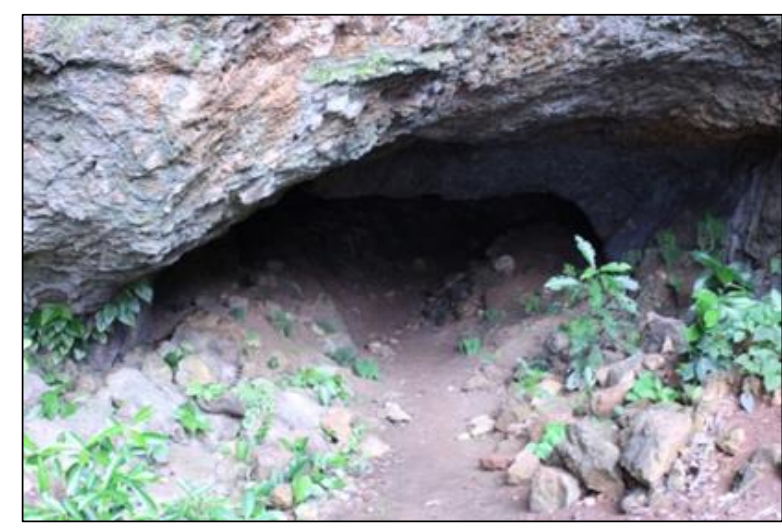

Gambar 6. Gua Jepang/Gua Hartakarun (Dok. Balai Arkeologi Jawa Barat, 2016)

Semua lubang tambang di kawasan Gunungmadur digali dan kemudian ditambang oleh para romusha. Tidak hanya itu, semua aktivitas pertambangan dari mulai persiapan sampai tahapan operasional dilakukan dengan menggunakan tenaga romusha yang didatangkan dari berbagai daerah di luar Banten, terutama Jawa Tengah dan Jawa Timur. Catatan Tan Malaka menunjukkan bahwa jumlah romusha di Bayah pada tahun-tahun awal mencapai 20.000 orang dan pada hampir menyerahnya Jepang, jumlahnya sekitar 10.000 orang (Malaka, 2014: 498).

\footnotetext{
${ }^{8}$ Wancara dengan Ibong (51 tahun) dan Sopandi (59 tahun), 2016.
}

Berdasarkan keahlian yang dimiliki, romusha di Bayah dikelompokkan menjadi dua kategori, yaitu romusha yang memiliki keahlian dan romusha yang tidak memiliki keahlian. Romusha yang memiliki keahlian adalah mereka yang sebelum dikirim ke Bayah sudah memiliki keahlian seperti masinis, pegawai stasiun, ahli di bidang mesin, survei lahan, ahli konstruksi jalan dan jembatan, serta ahli dalam penambangan. Romusha yang tidak memiliki keahlian adalah mereka yang tidak memiliki kemampuan/keahlian di bidang pertambangan atau bidang lainnya yang diperlukan di pertambangan Bayah (Kurasawa, 1993: 186). Berdasarkan kondisi fisik, romusha dibedakan menjadi tiga kelompok, yaitu (1) kelompok romusha dengan kondisi fisik lemah; (2) kelompok romusha dengan kondisi fisik sedang; dan (3) kelompok romusha dengan kondisi fisik yang prima. Pembagian kelompok berdasarkan kondisi fisik dilakukan agar memudahkan dalam penempatan di pertambangan Bayah. Adapun jenis pekerjaan di Pertambangan Bayah antara lain, bagian tambang, bagian transportasi, bagian bangunan, bagian kereta api, bagian bengkel mobil dan kereta api, bagian gudang, serta pesuruh di kantor dan rumah orang Jepang (Isnaeni \& Apid, 2008: 119-120).

Perekrutan romusha awalnya dilakukan secara sukarela dan terdiri atas para pengangguran yang mencari kerja dan dipekerjakan sebagai tenaga produktif atau buruh (Kurasawa, 1993: 124). Ketika permintaan tenaga kerja meningkat, maka sejak akhir 1943, Pemerintahan Jepang di Indonesia memobilisasi tenaga kerja secara sistematik dan intensif melalui slogan "Peningkatan Produksi" dan "Mobilisasi total" (Sato, 2000: 20). Perekrutan dilakukan tidak lagi mengandalkan perekrutan sukarelawan namun memerintahkan kepala desa untuk menyediakan warganya guna menjadi romusha. Pengumpulan tenaga kerja juga dilakukan Pasukan Jepang dengan menjalankan razia dan mengambil siapapun yang tertangkap di jalan untuk memperkuat barisan romusha guna memenuhi kebutuhan tenaga kerja. Laki-laki dan perempuan usia produktif di setiap desa/wilayah diinventarisir oleh kepala desa atau kepala wilayah, kemudian mereka dikenai kewajiban kerja tanpa terkecuali. Setiap saat sebuah badan yang berkaitan langsung dengan romusha

9 Wawancara dengan HMS. Badjadji (87 tahun), tokoh masyarakat Bayah, 2016. 
mengkondisikan penempatan romusha sesuai dengan kebutuhan angkatan perang. Kebijakan mobilisasi mereka dimaksudkan untuk menciptakan produktivitas akibat pengurangan produktivitas pertanian dan perkebunan di Jawa. Romusha juga merupakan komoditi yang diperlukan guna dipertukarkan dengan bahanbahan yang dibutuhkan dalam perang (Kurasawa, 1993: 124). Hal ini menunjukkan bahwa perekrutan romusha dilakukan secara lebih serius dengan alasan: (1) Kondisi perang yang semakin memburuk bagi Jepang; (2) Tuntutan untuk dapat memenuhi kebutuhan sendiri (swasembada) bagi tiap Angkatan Perang di daerah pendudukan; dan (3) Adanya motivasi ekonomi yang menyertai setiap pengerahan tenaga romusha (Isnaeni \& Apid, 2008: 57-58).

Para Romusha pada awalnya datang ke Bayah dengan tujuan memperbaiki kehidupan agar menjadi lebih baik, namun kenyataan berbicara lain. Selama menjalani tugas sebagai romusha, mereka harus bekerja berat dengan peralatan seadanya, mengalami banyak siksaan fisik dan mental, kurangnya asupan gizi, dan kondisi lingkungan yang tidak bersahabat. Banyak kecelakaan kerja terjadi di dalam lubang tambang. Pekerja romusha banyak yang tewas akibat kecelakaan tersebut. Mereka harus meregang nyawa akibat keracunan gas, tertimpa longsoran, dan bencana lainnya di dalam lubang tambang. Tidak ada catatan jumlah pasti berapa banyak romusha yang tewas di Bayah selama kegiatan pembangunan dan penambangan batu bara, termasuk pembangunan jalur kereta api Saketi-Bayah. Pada proyek pembangunan jalur kereta api Saketi-Bayah, jumlah romusha yang menjadi korban mencapai 90.000 jiwa (Baird, 2016: 2). Jenazah pekerja romusha yang tewas seringkali dikubur dengan tidak melalui proses ritual keagamaan. Mereka hanya dibungkus tikar dan dibalut dengan pakaian yang menempel di badannya. Pemakaman pun dilakukan di lokasi mayat itu ditemukan, bahkan saking banyaknya mayat romusha tidak sedikit satu lubang makam diisi oleh 5 (lima) sampai 10 (sepuluh) mayat. Salah satu pemakaman massal romusha berada di kawasan Deker, Pulomanuk, yang memiliki luas hingga mencapai 38 Ha. (Poeze, 1999: 303).

Saat ini areal pemakaman massal tersebut menjadi bagian dari kawasan Perkebunan Karet,

\footnotetext{
10 Wawancara dengan HMS. Badjadji (87 tahun), tokoh
} masyarakat Bayah, 2016 salah satunya tidak jauh dari Kampung Deker. Kondisi makam sudah tidak dapat dikenali karena nisannya sudah tidak ada dan lahannya sudah menjadi kebun karet. Menurut keterangan HMS. Badjadji (87 tahun), mereka yang dimakamkan adalah para romusha yang tewas di sekitar Pulomanuk. Mereka yang tewas di tempat lain akan dimakamkan di tempat di lokasi dia tewas. Sehingga, di sekitar lubang Sangko, kampung sawah, Cimanuk - Cibobos, dan Cimang juga terdapat kuburan massal para romusha. Salah seorang yang paling sering menguburkan mayat romusha terutama di sekitar Blok Madur, termasuk Pulomanuk dan Sawarna, adalah Amat Parino, seorang romusha asal Purworejo yang bertugas di bagian lubang. ${ }^{10}$

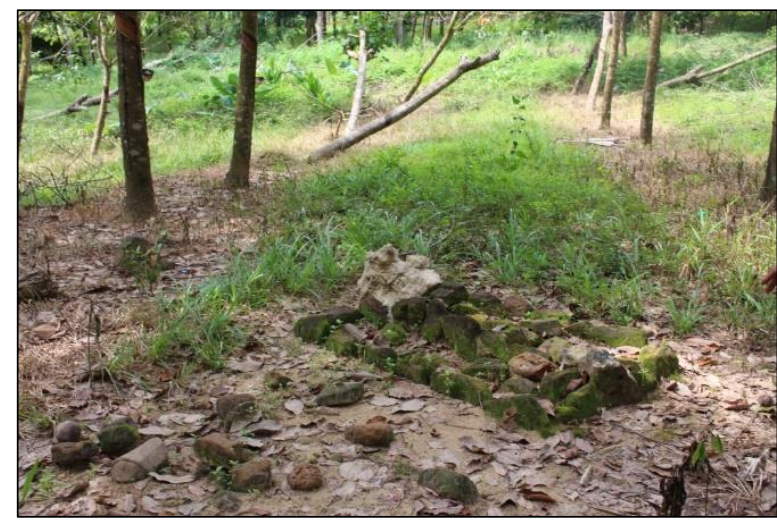

Gambar 7. Lokasi kuburan massal romusha di Kampung Deker, Pulomanuk, Bayah

(Sumber: Balai Arkeologi Bandung, 2015)

Romusha di Bayah meninggalkan luka mendalam bagi korban dan keluarganya. Hal inilah yang menjadikan ingatan komunal masyarakat akan romusha sedikit demi sedikit dihilangkan. Para mantan romusha enggan untuk menceritakan pengalaman mereka selama bekerja dan hidup di Bayah, terpisah jauh dari keluarga besar. Keengganan untuk menceritakan pengalamannya semasa menjadi romusha, karena mereka ingin melupakan apa yang pernah dialaminya dan berharap anak cucu tidak merasakan pahit getirnya menjadi romusha. ${ }^{11}$

\section{KESIMPULAN}

Bayah merupakan salah satu pusat aktivitas romusha di Banten. Kandungan potensi batu bara di bumi Bayah menjadikannya memiliki kedudukan istimewa di masa Pendudukan Jepang.

11 Wawancara dengan H.M.S. Badjaji (87 tahun), Tokoh Masyarakat Bayah, 2016. 
Batu bara Bayah menjadi solusi bagi kemandirian Pulau Jawa pada bidang energi. Pengerahan tenaga kerja dilakukan guna menambang batu bara di Bayah. Lubang-lubang tambang utama digali menembus bukit guna mencapai batu bara. Pekerjaan berat tersebut dilakukan dengan menggunakan peralatan sederhana dan seadanya. Beratnya pekerjaan, kondisi lingkungan yang tidak bersahabat, siksaan fisik dari tentara Jepang yang mengawasi, dan asupan makanan yang tidak memadai merupakan bentuk penderitaan yang dirasakan para romusha selama mereka bekerja di Bayah. Korban romusha yang berjatuhan dikubur secara massal di tempat mereka tewas. Lubanglubang tambang yang menganga di kaki bukit kawasan Gunungmadur, Bayah seperti lubang Sanko, lubang Cigalucur, dan lubang Cipicung, serta keberadaan kuburan massal di banyak titik kawasan pertambangan Bayah merupakan bukti beratnya pekerjaan para romusha menambang batu bara Bayah.

\section{Ucapan Terima Kasih}

Tulisan ini dapat terwujud karena adanya dukungan dan bantuan banyak pihak, untuk itu pada kesempatan ini Penulis menyampaikan terima kasih yang sebesar-besarnya kepada: Tim Penelitian tentang Tinggalan Perkeretaapian Masa Pendudukan Jepang pada Jalur SaketiBayah, Lebak Banten (2015); Tim Penelitian tentang Tinggalan Perkeretaapian dan Jejak Romusha di Kecamatan Bayah, Lebak Banten (2016); Bapak HMS. Badjadji, 87 tahun, Tokoh Masyarakat Bayah yang telah memberikan informasi berkenaan dengan kehidupan romusha di Bayah; serta Bapak Atok (74 tahun), Bapak Iyar (50 tahun), dan Bapak Supandi (59 tahun) yang telah memberikan informasi tentang keberadaan Lubang tambang Jepang di Bayah.

$* * * * *$

\section{DAFTAR PUSTAKA}

Baird, J. K. (2016). War Crimes in Japan-Occupied Indonesia: Unraveling the Persecution of Achmad Mochtar. The Asia-Pacific Journal | Japan Focus, 14(1), 1-10.

Frederick, W. H. (1989). Pandangan dan Gejolak: masyarakat kota dan lahirnya revolusi Indonesia (Surabaya 1926-1946). Jakarta: Gramedia.

Hermawan, I. (2013). Laporan Penelitian Arkeologi Pertambangan Emas Cikotok, Kabupaten Lebak
Provinsi Banten. Bandung: Balai Arkeologi Bandung.

Hermawan, I. (2014). Lori Gantung: Transportasi Hasil Tambang di Pertambangan Emas Cikotok. Purbawidya: Jurnal Penelitian dan Pengembangan Arkeologi, 3(1), 15-26.

Hermawan, I. (2015). Tinggalan Perkeretaapian Masa Jepang pada Jalur Kereta Api Lintas Saketi Bayah, Kabupaten Lebak Provinsi Banten. Bandung.

Hermawan, I. (2016). Tinggalan Perkeretaapian Masa Jepang dan Jejak Romusa di Kecamatan Bayah, Kabupaten Lebak Provinsi Banten. Bandung.

Ibrahim, J. (2004). Eksploitasi Ekonomi Pendudukan Jepang di Surakarta. Humaniora journal of culture, literature, and linguistics, 16(1), 35-49.

Isnaeni, H. F., \& Apid. (2008). Romusa: Sejarah yang Terlupakan. Yogyakarta: Ombak.

Kurasawa, A. (1993). Mobilisasi dan kontrol: studi tentang perubahan sosial di pedesaan Jawa, 1942-1945. Jakarta: Yayasan Karti Sarana dengan Penerbit PT Gramedia Widiasarana.

Malaka, T. (2005). Merdeka 100\%: Tiga Percakapan Ekonomi-Politik. Tangerang: Marjin Kiri.

Malaka, T. (2014). Dari Penjara ke Penjara. Yogyakarta: Penerbit Narasi.

Nagazumi, A. (1988). Pemberontakan Indonesia di Masa Pendudukan Jepang. Jakarta: Yayasan Obor Indonesia.

Perdana, N. A. (2010). Pengaruh Pendudukan Jepang terhadap Masyarakat Magelang 1942-1945. Paramita, 20(2).

Poeze, H. A. (1999). Tan Malaka 1926 - 1945: Pergulatan Menuju Republik. Jakarta: Pustaka Utama Grafiti.

Rohmanudin, E. (2012). Peristiwa Romusa di Bayah Lebak Banten Selatan (1942 - 1945). Serang: Institut Agama Islam Negeri Sultan Maulana Hasanuddin, Serang, Banten.

Sato, S. (2000). Labour Relations in Japanese Occupied Indonesia (CLARA Working Paper No. 8). Amsterdam. Retrieved from https://socialhistory.org/sites/default/files/docs/ publications/clara-wp08.pdf

Sujatmiko, \& Santosa, S. (1992). Peta Geologi Lembar Leuwidamar, Jawa (ke tiga). Bandung: Pusat Survei Geologi.

Tim Telaga Bakti Nusantara. (1997). Sejarah Perkeretaapian Indonesia Jilid 1. Bandung: Angkasa.

Van Bemmelen, R. W. (1949). The Geology of Indonesia. General Geology of Indonesia and Adjacent Archipelagoes. The Hague: Martinus Nijhoff.

Yuliati, D. (2010). Sistem Propaganda Jepang di Jawa 1942-1945. Retrieved from http://eprints.undip.ac.id/19444/1/ARTIKEL_P ROPAGANDA_JEPANG.pdf 